\title{
An integrative in vitro approach to analyse digestion of wheat polysaccharides and the effect of enzyme supplementation
}

\author{
Mickaël Lafond ${ }^{1}$, Bernard Bouza ${ }^{2}$, Sandrine Eyrichine ${ }^{3}$, Estelle Bonnin ${ }^{3}$, Emmanuelle H. Crost ${ }^{2}$, \\ Pierre-André Geraert ${ }^{2}$, Thierry Giardina ${ }^{1}$ and El Hassan Ajandouz ${ }^{1 *}$ \\ ${ }^{1}$ BiosCiences ISM2 UMR-CNRS-6263, Université Paul Cézanne Aix Marseille III, Avenue Escadrille Normandie-Niemen, \\ 13397 Marseille Cedex 20, France \\ ${ }^{2}$ CERN Adisseo France SAS, Route de Chamblet, 03600 Commentry, France \\ ${ }^{3}$ INRA, UR 1268, Biopolymères Interactions Assemblages, 44316 Nantes Cedex 03, France
}

(Received 3 February 2010 - Revised 4 January 2011 - Accepted 7 January 2011 - First published online 18 April 2011)

\section{Abstract}

The digestion of polysaccharides from the wheat cultivars Caphorn and Isengrain was investigated, and the efficiency of an enzyme preparation was tested using the TNO gastrointestinal model (TIM-1). The apparent digestibility (AD) of carbohydrates was determined based on the measurement of organic matter (OM), total monosaccharides, reducing ends (RE) and end products (EP: glucose, maltose and xylobiose). The $\mathrm{AD}$ of the $\mathrm{OM}$ from Caphorn and Isengrain measured using caecectomised cockerels did not differ from that measured using TIM-1: 72.0 (SD 2.6) $v .70 \cdot 6$ (SD 0.6) \% for Caphorn $(P=0.580)$ and 73.0 (SD 2.3) $v .71 \cdot 1$ (SD 1.9) \% for Isengrain $(P=0.252)$. After the $6 \mathrm{~h}$ TIM-1 digestion, $41 \cdot 4-58 \cdot 9 \%$ of the OM, RE and EP were recovered from the jejunal compartment and $18 \cdot 3-27 \cdot 1 \%$ from the ileal compartment, while ileal deliveries and digestive residues constituted the remainder. A commercial enzyme cocktail tested at $0 \cdot 2 \mu \mathrm{l} / \mathrm{g}$ of wheat improved TIM-1 digestibility of Caphorn and Isengrain polysaccharides: $3.9 \%(P=0.0203)$ and $3.4 \%(P=0.0058)$ based on the OM; $9 \cdot 7 \%(P<0 \cdot 0001)$ and $3.1 \%(P=0.031)$ based on the total glucose; $47.2 \%(P<0.0001)$ and $14.2 \%(P=0.0004)$ based on the RE, respectively. The enzyme cocktail improved the release of the EP for Caphorn $(3.8 \%, P=0.008)$ but not for Isengrain $(-0.8 \%, P=0.561)$. The higher efficiency of the enzyme supplementation on the digestion of Caphorn polysaccharides compared with Isengrain seems to be linked to the higher soluble carbohydrate contents and/or less ramified arabinoxylan of Caphorn.

\section{Key words: Wheat cultivars: Enzyme supplementation: In vitro TNO gastrointestinal model-1: Polysaccharide digestibility} markers

Wheat is generally used as a major source of energy in animal diets $^{(1)}$. In the European poultry diet, for example, wheat accounts for more than $600 \mathrm{~g} / \mathrm{kg}^{(2)}$. The major components of wheat are starch and proteins, whereas NSP derived from the cell walls account for only $3-8 \%$ of the total mass of wheat grain ${ }^{(3)}$. Starch is the major source of energy, whereas NSP are generally considered as anti-nutritional factors because they are non-digestible, highly hydrophilic and may be chelators of minerals such as $\mathrm{Ca}$ or $\mathrm{Fe}^{(4)}$. About half of NSP in mass is constituted by arabinoxylan (AX) polymers ${ }^{(3,5)}$. The content and structure of AX polymers show large differences between wheat cultivars, which affect the end-use properties and nutritional quality of the grain. Furthermore, the different degrees of substitution of the xylan chain, composed mainly of arabinose and phenolic compounds, are correlated with the viscosity and digestibility of wheat carbohydrates ${ }^{(6,7)}$.
Single-stomached animals, especially poultry, lack NSPdegrading enzymes so that the accessibility of $\alpha$-amylase to wheat starch is limited. Consequently, in order to improve the metabolisable energy of wheat-based poultry diets, the effectiveness of NSP enzymes has been exhaustively stu$\operatorname{died}^{(8-10)}$, and numerous enzyme preparations and cocktails have been marketed. Besides in vivo tools, which are rather hard to use, in vitro models, such as the TNO gastrointestinal model $(\mathrm{TIM})^{(11)}$, mimicking the gastrointestinal tract, have emerged as efficient tools for investigating carbohydrate digestion, targeting the feed and food sectors. Indeed, it has recently been shown that high repeatability of $\beta$-glucan digestibility values could be obtained in TIM-1, and the digestibility values of resistant starch obtained using the same model have been found to be similar to those obtained in ileostomy patients $^{(12,13)}$. In addition, using this in vitro model and AX

Abbreviations: AOMd, apparent organic matter digestibility; AX, arabinoxylan; HPAEC-PAD, high-performance anion exchange chromatography coupled with a pulsed amperometric detection; TIM, TNO gastrointestinal model. 
extracted from different wheat cultivars, it has been shown that the AX structure might influence the improvement of digestibility due to supplementation with NSP-degrading enzymes ${ }^{(14)}$. Although the main target of NSP enzymes is the soluble AX fraction, it has been demonstrated that the addition of some enzymes also targets the insoluble AX fraction ${ }^{(10)}$. However, the relationships between wheat characteristics and the responses of wheat batches to enzyme addition are not yet fully understood.

In the present study, two wheat cultivars, Caphorn and Isengrain, were chosen, based on their monosaccharide composition, to investigate carbohydrate digestibility in TIM-1. The in vitro model was first compared with caecectomised cockerels, with regard to the apparent digestibility of organic matter. The AD of Caphorn and Isengrain carbohydrates was then determined based on the analysis of organic matter, reducing ends and end products in the TIM-1 compartments: jejunal and ileal dialysates (absorbed fraction), ileal delivery (non-absorbed fraction) and the residues that remained in the TIM- 1 compartments after the $6 \mathrm{~h}$ digestion trial. Finally, the digestion kinetics of Caphorn and Isengrain carbohydrates in the presence or absence of an enzyme supplement was followed in TIM-1 based on the measurements of the three aforementioned digestibility markers and of total monosaccharides. Using such an integrative approach, the objective was to obtain both an overview of and molecular information on the enzymatic digestion of wheat carbohydrates and on the benefits to be expected regarding supplementation with commercial enzymes.

\section{Materials and methods}

\section{Materials}

The enzyme preparation (Rovabio ${ }^{\text {TM }}$ Excel LC) was obtained from Adisseo SAS (Commentry, France). It consists of a Penicillium funiculosum secretome containing more than nineteen glycolytic and two proteolytic activities. Endo$\beta(1,4)$-xylanase, endo- $\beta$-(1,3)-glucanase, cellobiohydrolase and endo- $\beta(1,4)$-glucanase account for the main glycolytic activities $^{(15,16)}$, whereas proteomic analysis revealed the existence of fifty distinct proteins in this secretome ${ }^{(17)}$. The wheat cultivars Aztec, Tapidor, Oratorio, Apache, Caphorn and Isengrain were purchased from Euronutrition (St Symphorien, France). Trypsin from bovine pancreas, pepsin from porcine gastric mucosa and porcine bile extract were purchased from Sigma (St-Quentin-Fallavier, France), whereas Rhizopus lipase was purchased from Amano Enzyme Europe, and the pancreatin solution was from Paines \& Byrne (Greenford, Middlesex, UK).

\section{Digestion medium}

The digestion medium designed for the digestion trials in TIM-1 was based on a previous report ${ }^{(14)}$, with some modifications. It was composed of $45 \mathrm{~g}$ (dry basis) ground wheat (grinding screen size $3 \mathrm{~mm}$ ), $85 \mathrm{~g}$ of gastric salt solution $\left(\mathrm{NaCl} 1 \mathrm{~g} / 1, \mathrm{KCl} 1 \cdot 1 \mathrm{~g} / \mathrm{l}\right.$ and $\mathrm{CaCl}_{2}$ dihydrate $\left.0 \cdot 15 \mathrm{~g} / \mathrm{l}\right), 5 \mathrm{~g}$ pepsin and lipase solution (90000 and $11200 \mathrm{U} / \mathrm{mg}$, respectively) and $170 \mathrm{~g}$ of water. (One unit of pancreatic lipase is the quantity of enzyme that catalyses the formation of $1.0 \mu \mathrm{mol}$ fatty acid from TAG in $1 \mathrm{~h}$ at $37^{\circ} \mathrm{C}$ and $\mathrm{pH} 7.7$ using olive oil, and one unit of porcine pepsin corresponds to an increase of absorbance (at $280 \mathrm{~nm}$ ) of 0.001 unit per min measured at $37^{\circ} \mathrm{C}$ and $\mathrm{pH} 2.0$ using $\mathrm{Hb}$ as substrate.) When added, Rovabio was at $0 \cdot 2 \mu \mathrm{l} / \mathrm{g}$ of wheat.

\section{In vivo digestibility assays}

The in vivo experimental procedure involving animals was approved (C-03-159-4) by the Departmental Direction of the Veterinary Services (Allier, France). Apparent organic matter digestibility (AOMd) was determined for caecectomised cockerels using the method based on wet force-feeding and total excreta collection ${ }^{(18)}$. A total of twelve roosters (age 13 months and weight 3.45 (SD 0.15$) \mathrm{kg}$ ) per diet were randomly distributed in individual cages, which were placed in a temperature-controlled room. After $24 \mathrm{~h}$ of fasting, the cockerels were force-fed with $110 \mathrm{~g}$ of meal ( $96 \%$ wheat and $4 \%$ mineral-vitamin mixture). The excreta were collected at 24 and $48 \mathrm{~h}$ after force-feeding, and pooled, weighed, freeze-dried and stored until analysis of the DM and ash contents. Analysis of the DM and ash contents was also performed for diet ingesta.

\section{Wheat digestion assays in TNO gastrointestinal model-1}

A schematic diagram of TIM-1 (installed at the Centre of Expertise Research and Nutrition, Adisseo, Commentry, France) is shown in Fig. 1. The in vitro model allows the control of digestive secretions, $\mathrm{pH}$, temperature and peristaltism. The protocol of Minekus et al. ${ }^{(11)}$, which is adapted for pigs, was utilised along with a few modifications that targeted conditions of poultry digestion. In this in vitro model, gastric and ileal deliveries $(f)$ are described by the equation $f=1-2^{-\left(t / t^{1 / 2}\right) \beta}$, where $t^{1 / 2}$ is the half-time of delivery and $\beta$ accounts for the shape of the time-course delivery curve. In the present study, for gastric delivery, $t^{1 / 2}$ and $\beta$ were set at $120 \mathrm{~min}$ and 1 , respectively, whereas for small-intestinal delivery, $t^{1 / 2}$ and $\beta$ were set at $400 \mathrm{~min}$ and $2 \cdot 17$, respectively. The $\mathrm{pH}$ set for the gastric compartment was $6 \cdot 5,5 \cdot 0,4 \cdot 0,3 \cdot 0$, 2.5 and 2.0 at $0,60,120,180,240$ and $300 \mathrm{~min}$, respectively. The $\mathrm{pH}$ for the duodenal, jejunal and ileal compartments was $6 \cdot 5,6 \cdot 8$ and $7 \cdot 2$, respectively. Before starting the digestibility trials, the duodenal compartment was flushed with $1 \mathrm{ml}$ of trypsin solution $(2 \mathrm{mg} / \mathrm{ml}), 7.5 \mathrm{ml}$ of pancreatin solution $(7 \%$, $\mathrm{w} / \mathrm{w}), 15 \mathrm{ml}$ of bile extract solution and $32 \mathrm{ml}$ of small-intestinal salt solution $\left(\mathrm{NaCl} 5 \mathrm{~g} / 1, \mathrm{KCl} 0.6 \mathrm{~g} / 1\right.$ and $\mathrm{CaCl}_{2}$ dihydrate $0.3 \mathrm{~g}$ / 1). The jejunal and ileal compartments were filled with $130 \mathrm{ml}$ of the small-intestinal salt solution. The absorption was mimicked using haemodialyser HG-400 membranes with a cut-off of 5-10 kDa (Hospal Cobe, Lyon, France). The dialysis fluid was pumped at $10 \mathrm{ml} / \mathrm{min}$ and collected in the intervals $0-60,60-120,120-180,180-240$ and $240-360 \mathrm{~min}$. The samples were weighed and stored at $-20^{\circ} \mathrm{C}$ until analysis. The ileal effluents were collected between 0 and 120, 120

\footnotetext{
(NaCl $1 \mathrm{~g} / \mathrm{LCl} 1 \cdot 1 \mathrm{~g} / \mathrm{l}$ and $\mathrm{CaCl}_{2}$ dihydrate $\left.0 \cdot 15 \mathrm{~g} / \mathrm{l}\right), 5 \mathrm{~g}$
} 


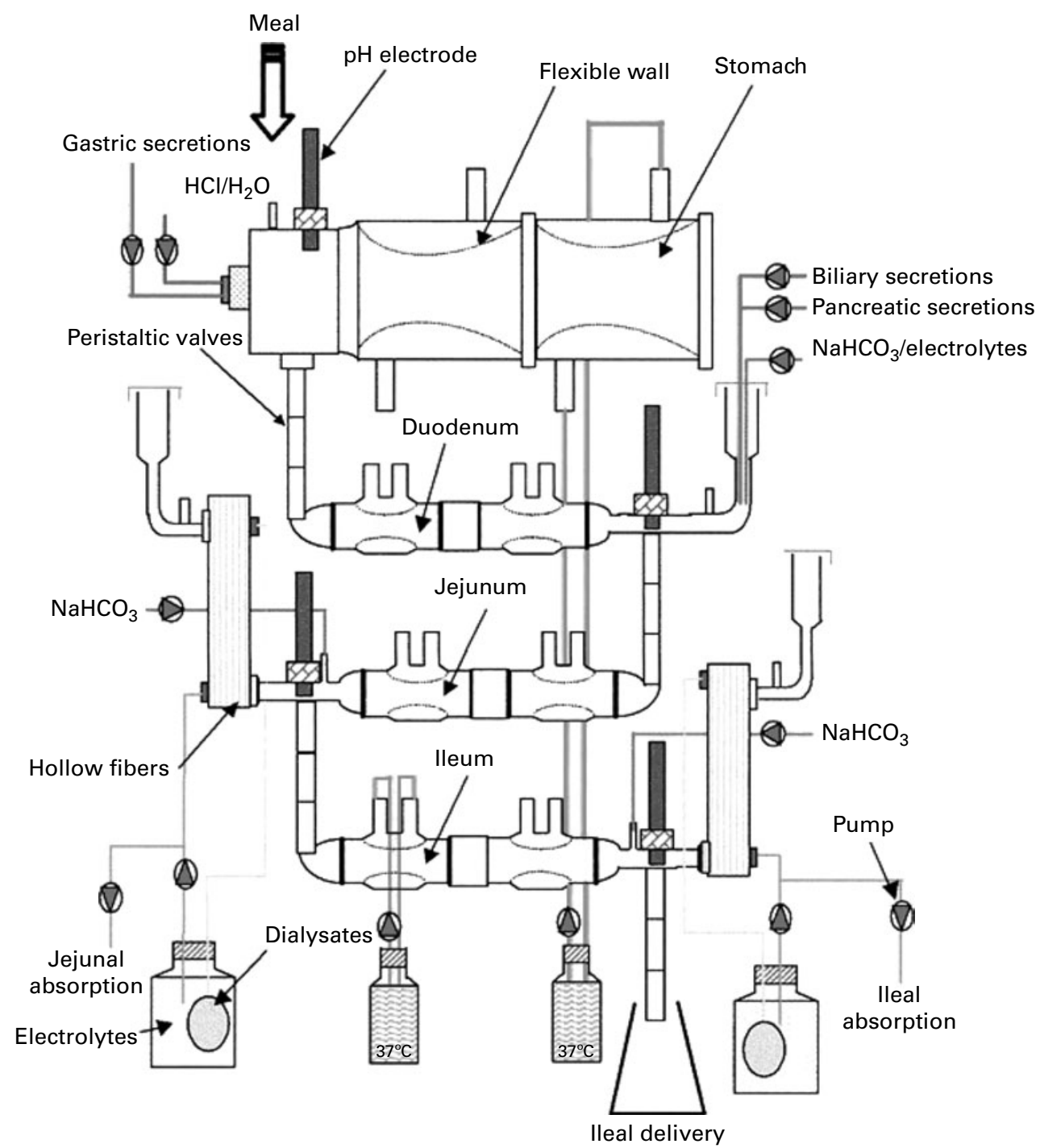

Fig. 1. Schematic diagram of the gastrointestinal digestion model (TNO gastrointestinal model-1).

and 180, 180 and 240 and 240 and $360 \mathrm{~min}$, weighed and stored at $-20^{\circ} \mathrm{C}$. The residues in the gastroduodenal and jejunoileal compartments were separately collected at the end of the experiment. The digestion assays in TIM-1 were carried out in duplicate.

\section{Analysis}

The dialysed samples were used without any treatment, whereas the suspensions from the ileal deliveries and the residues were rapidly defrosted and centrifuged at $14000 \boldsymbol{g}$ for $10 \mathrm{~min}$, and the pellets and the supernatants were stored at $-20^{\circ} \mathrm{C}$ until analysis. The supernatants and the dialysed samples were used for the measurement of the reducing ends and end products. Both the supernatants and the pellets were used for GC analysis, whereas the organic matter fraction was determined without centrifugation. Analysis of the DM and inorganic matter was performed by Institut Louise Blanquet (Clermont-Ferrand, France), based on a reference $\operatorname{method}^{(19)}$.
Total monosaccharides. The monosaccharide composition of the wheat cultivars Aztec, Tapidor, Oratorio, Apache, Caphorn and Isengrain and that of the supernatants and the pellets recovered from the TIM-1 experiments with Caphorn and Isengrain were determined by GC after acid hydrolysis ${ }^{(20)}$. Briefly, the liquid fractions were hydrolysed with $4 \mathrm{M}-\mathrm{H}_{2} \mathrm{SO}_{4}$ in the presence of inositol as the internal standard $(5 \mathrm{~g} / \mathrm{l})$ for $2 \mathrm{~h}$ at $100^{\circ} \mathrm{C}$, whereas the pellets were pre-hydrolysed with $26 \mathrm{~N}-\mathrm{H}_{2} \mathrm{SO}_{4}$ for $30 \mathrm{~min}$ at $25^{\circ} \mathrm{C}$ before inositol was added. After cooling, the mixture was neutralised with an ammoniac solution $(25 \%, \mathrm{v} / \mathrm{v})$ and then reduced $\left(1 \mathrm{~h}\right.$ at $\left.40^{\circ} \mathrm{C}\right)$ with $3 \mathrm{M}-\mathrm{NaBH}_{4}$. Acetylation was performed at room temperature using acetic anhydride in the presence of $\mathrm{N}$-methylimidazole. Finally, the acetylated samples were extracted with dichloromethane and injected in the GLC system (Perkin-Elmer Autosystem, Covina, CA, USA) using a $25 \times 0.32 \mathrm{~mm}$ silica column (BP-225; SGE, Ringwood, VIC, Australia) and a flame ionisation detector. The AX content was calculated as the sum of 
Table 1. Carbohydrate composition* and arabinoxylan ramification of Caphorn and Isengrain wheat cultivars†

\begin{tabular}{lcccccccc}
\hline & Glc & Xyl & Ara & Gal & Man & Total & AX & A:X \\
\hline Total & & & & & & & & \\
$\quad$ Caphorn & 74.49 & 4.84 & 2.80 & 0.66 & 0.37 & 83.15 & 7.64 & 0.58 \\
$\quad \begin{array}{l}\text { Isengrain } \\
\text { Solublef }\end{array}$ & 75.27 & 4.00 & 2.40 & 0.56 & 0.49 & 82.72 & 6.40 & 0.60 \\
$\quad$ Caphorn & 2.77 & 0.77 & 0.52 & 0.19 & 0.03 & 4.28 & 1.30 & 0.68 \\
$\quad$ Isengrain & 0.69 & 0.29 & 0.25 & 0.14 & 0.03 & 1.40 & 0.54 & 0.87 \\
\hline
\end{tabular}

Glc, glucose; Xyl, xylose; Ara, arabinose; Gal, galactose; Man, mannose; AX, arabinoxylan; A:X, arabinose:xylose molar ratio.

${ }^{*}$ Expressed in $\mathrm{g} / 100 \mathrm{~g}$ of dry mass.

† All samples were analysed in triplicate.

$\ddagger$ Monosaccharides of the soluble fraction extracted from $1 \mathrm{~g}$ of ground wheat grain in $4 \mathrm{ml}$ of water.

arabinose and xylose. Each determination was performed in triplicate.

Reducing ends. The liberated reducing ends were determined according to the dinitrosalicylic acid method ${ }^{(21)}$, using ninety-six-well microplates and a KRL microplate spectrophotometer (Kirial International, Couternon, France). The blank contained water instead of the sample. The data are expressed as absorbance units, since the extinction coefficients varied strongly depending on the nature of the reducing product (data not shown).

End products. The end products were analysed using a high-performance anion exchange chromatography coupled with a pulsed amperometric detection (HPAEC-PAD) system equipped with a Carbo-Pac PA-100 $(250 \times 4 \mathrm{~mm})$ column, an ED40 electrochemical detector (Dionex Corporation, Sunnyvale, CA, USA) and an AS3500 autosampler (Thermoelectron, Courtaboeuf, France). Appropriate sample dilution was performed before injection (typically $20 \mu \mathrm{l}$ ) onto the HPAEC system. Elution $(1 \mathrm{ml} / \mathrm{min})$ was carried out using a $20 \mathrm{~min}$ linear gradient program from 100\% A (5mm-NaOAc and $80 \mathrm{~mm}-\mathrm{NaOH})$ to $30 \% \mathrm{~A}$ and $70 \% \mathrm{~B}(500 \mathrm{~mm}-\mathrm{NaOAc}$ and $80 \mathrm{~mm}-\mathrm{NaOH}$ ). The peaks of the HPAEC-PAD chromatograms were identified based on the standard curves of xylo- and malto-oligosaccharides, containing up to six units of xylose and glucose (Sigma-Aldrich), respectively, with 3\% of maximal deviations in the retention times. Chromeleon ${ }^{\circledR}$ software
(Dionex) was used for data acquisition and processing. Each determination was performed in triplicate.

\section{Calculation of digestibility and statistical analysis}

AOMd from caecectomised cockerels was calculated as percentage of intake:

$$
\operatorname{AOMd}(\%)=100 \times(1-(\text { OM excreted/OM ingested })) .
$$

For the in vitro model TIM-1, the digestibilities of organic matter, total monosaccharides and end products are expressed as follows:

$$
\begin{aligned}
\operatorname{DX}_{i}(\%)= & 100 \times\left(\text { dialysis } x_{i} /\left(\sum \left(\text { dialysis } x_{0-360}\right.\right.\right. \\
& \left.\left.\left.+ \text { ileal delivery } x_{0-360}\right)+\left(\text { residues } x_{0-360}\right)\right)\right),
\end{aligned}
$$

where $x$ is the digestibility marker and $i$ is the time of cumulative recovery (at 60, 120, 180, 240 and $360 \mathrm{~min}$ ). The residues were the remaining part of the meal in the TIM- 1 compartments after digestion experiments.

Statistical analysis of repeated-measures data was performed using the mixed procedure of SAS 9.1.3 (SAS Institute, Inc., Cary, NC, USA). As the values were cumulated over time, the covariance structure was specified as 'Auto Regressive type 1'. The restricted maximum-likelihood method was used to estimate covariance parameters, and the tests of fixed effects (in model, contrasts and least-squares means)

Table 2. Repartition (\%)* of organic matter, reducing ends and end products from Isengrain and Caphorn

\begin{tabular}{|c|c|c|c|c|c|c|c|}
\hline & \multicolumn{2}{|c|}{ Jejunal dialysis } & \multicolumn{2}{|c|}{ Ileal dialysis } & \multicolumn{2}{|c|}{ Ileal deliveries } & \multirow{2}{*}{$\begin{array}{l}\text { Gastrointestinal } \\
\text { residues }\end{array}$} \\
\hline & Mean & SD & Mean & SD & Mean & SD & \\
\hline \multicolumn{8}{|l|}{ Isengrain } \\
\hline Organic matter & 55.4 & 0.2 & $18 \cdot 6$ & 0.1 & $15 \cdot 4$ & 0.9 & $10 \cdot 6$ \\
\hline Reducing ends & 58.9 & $4 \cdot 3$ & $25 \cdot 7$ & 1.5 & $8 \cdot 7$ & 1.4 & 6.7 \\
\hline End products & $41 \cdot 4$ & 0.4 & $23 \cdot 6$ & $3 \cdot 1$ & $21 \cdot 6$ & 1.5 & $13 \cdot 4$ \\
\hline \multicolumn{8}{|l|}{ Caphorn } \\
\hline Organic matter & $56 \cdot 5$ & 0.8 & $18 \cdot 3$ & 0.7 & $16 \cdot 2$ & 2.5 & $9 \cdot 0$ \\
\hline Reducing ends & $58 \cdot 1$ & $13 \cdot 1$ & $27 \cdot 1$ & $5 \cdot 6$ & 11.5 & $6 \cdot 8$ & $3 \cdot 3$ \\
\hline End products & $45 \cdot 1$ & $3 \cdot 2$ & $23 \cdot 7$ & $3 \cdot 2$ & $16 \cdot 6$ & $8 \cdot 7$ & $14 \cdot 6$ \\
\hline
\end{tabular}
wheat cultivars in the TNO-gastrointestinal model-1 compartments

(Mean values and standard deviations)

* For each digestibility marker, $100 \%$ represents the sum of the cumulative values at 360 min of all the TNO gastrointestinal model-1 compartments. 

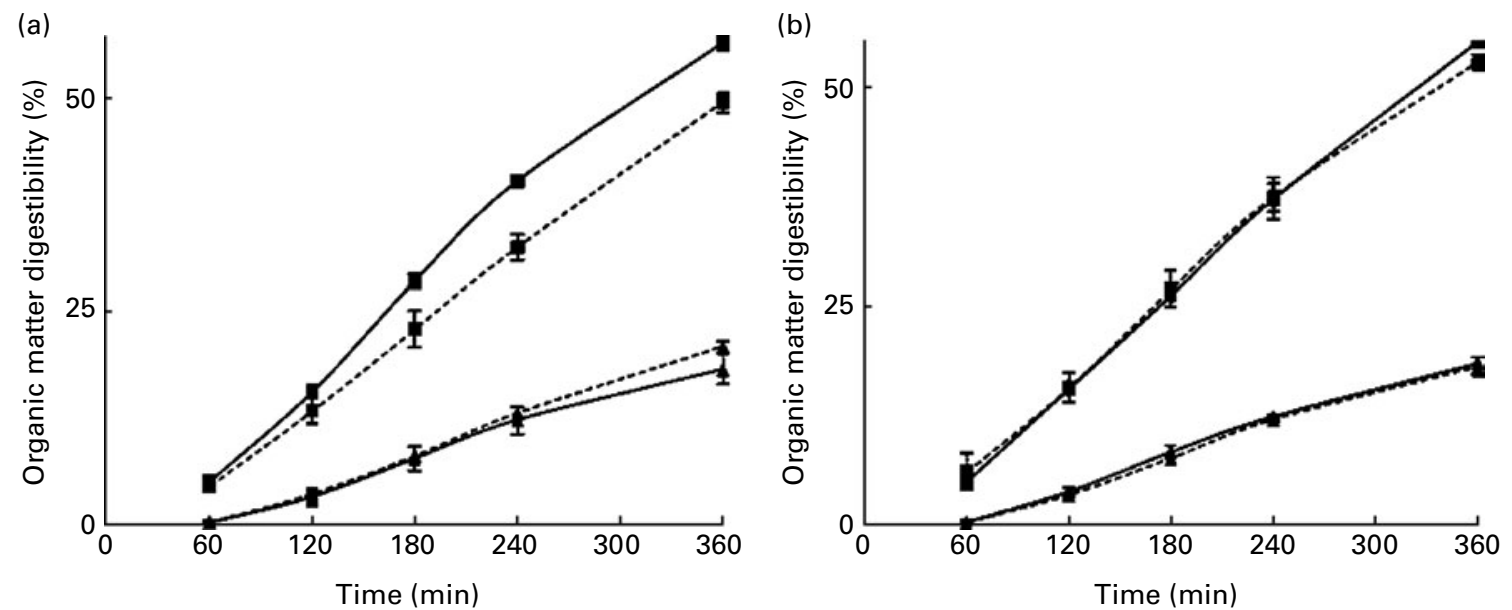

Fig. 2. Cumulative time course of the TNO gastrointestinal model-1 digestibility of organic matter from (a) Caphorn and (b) Isengrain in the presence ( - ) or absence (---) of Rovabio ${ }^{\mathrm{TM}}$ Excel in the jejunal $(\mathbf{\square})$ and ileal $(\mathbf{\Lambda})$ dialysates. Each determination was performed in triplicate.

were performed using the residual df (using the 'ddfm $=$ RESIDUAL' option). Time was specified as the factor of repeatedmeasures ANOVA determinations. Focusing on each compartment (jejunum and ileum) and their sum, the following multifactor statistical model was used to study the enzyme effects on the polysaccharide digestion processes:

$$
\begin{aligned}
Y= & \alpha+\beta_{i} \times \text { wheat }+\chi_{j} \times \text { treat }+\delta_{k} \times \operatorname{Exp}+\pi_{l} \times \text { time }+\eta_{i j} \\
& \times(\text { treat } \times \text { wheat })+\mu_{j j l} \times(\text { treat } \times \text { wheat } \times \text { time })+\varepsilon_{i j k l},
\end{aligned}
$$

where $\alpha$ is the meaning effect; $\beta, \chi, \delta, \eta, \pi$ and $\mu$ are the adjusted coefficients of the fixed effects in the model; $\varepsilon$ is the random error associated with the $j$ th treatment in experiment $k$ assigned to the $i$ th wheat at time $l$; subscripts $i, j, k$ and $l$ are the df of each factor: two wheat cultivars, two treatments, two experiments, five times.

Regarding the effects of enzyme preparation on each cultivar, as the interaction 'treatment $\times$ wheat $\times$ cumulative

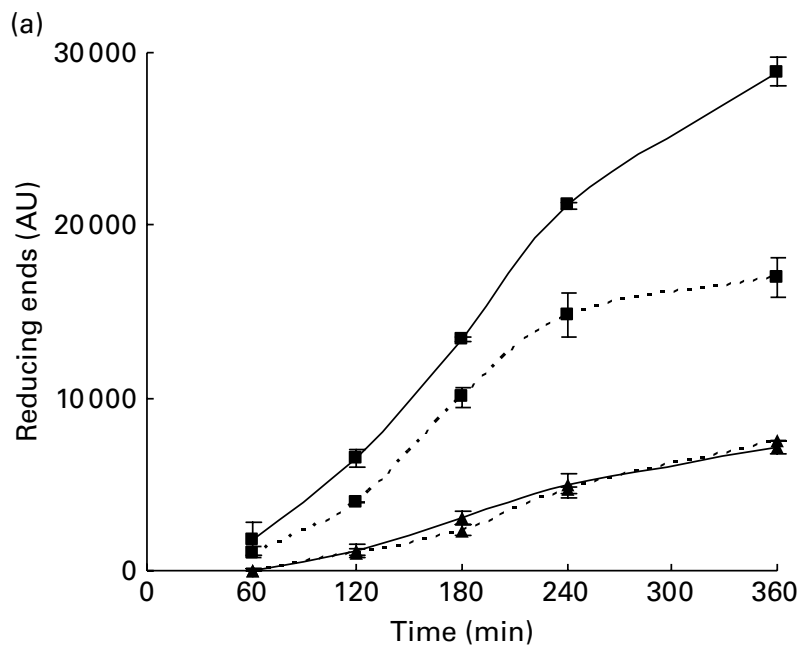

time' was significant, a SLICE option was added to the LSMEANS statement in order to compute the treatment effect at each time for both cultivars separately. Moreover, contrasts were computed (using the ESTIMATE statement) to compare the difference between cultivar controls at each time. All statistical analyses were considered to be significant at $P<0 \cdot 05$.

\section{Results and discussion}

\section{Carbohydrate composition of Caphorn and Isengrain wheat cultivars}

Among the six wheat cultivars tested, Caphorn and Isengrain exhibited the largest difference regarding the monosaccharide composition and the degree of AX ramification and were thus chosen for in vivo and in vitro studies. The individual monosaccharide content, the AX content and the arabinose:xylose molar ratio in the whole grain and in the soluble fraction of both Caphorn and Isengrain wheat cultivars are shown in

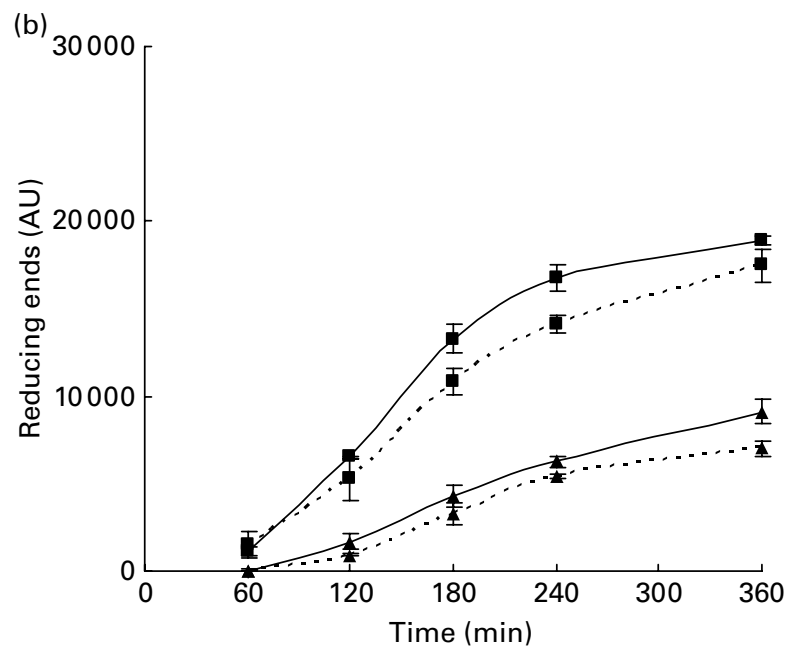

Fig. 3. Cumulative time-course appearance of the reducing ends from (a) Caphorn and (b) Isengrain in the presence (-) or absence (---) of Rovabio ${ }^{\mathrm{TM}}$ Excel in the jejunal $(\boldsymbol{\square})$ and ileal $(\mathbf{\Delta})$ dialysates. $\mathrm{AU}$, absorbance unit reflecting the content of the reducing ends recovered in the dialysates (see text for details). Each determination was performed in triplicate. 
Table 1. The individual monosaccharide content was found to be similar in the whole grain for both cultivars. The total monosaccharide content was also found to be similar in the whole grain $(83.2 \%$ in Caphorn $v .82 .7 \%$ in Isengrain). Glucose accounted for $89.6 \%$ of the total monosaccharides in Caphorn and for $91.0 \%$ of Isengrain total monosaccharides. Previous studies have shown that glucose from starch represents about $85 \%$ of wheat carbohydrates ${ }^{(3,5)}$, which suggests that NSP glucose amounts to $5 \%$ of the total wheat monosaccharides. Interestingly, the total monosaccharide content was three times higher in the Caphorn than in the Isengrain soluble fraction, and the $\mathrm{AX}$ content was also higher. The soluble fraction, although accounting for only a few mass percentage units, should play an important role, as a positive correlation has previously been observed between the content of soluble AX and the relative viscosity that has an impact on the rheological behaviour of the chyme ${ }^{(14)}$. Moreover, the lower A:X ratio in the Caphorn than in the Isengrain soluble fraction predicts different enzyme susceptibilities for the two water-soluble fractions, as the arabinose content in AX affects the xylanase activity ${ }^{(22)}$.
In vitro v. in vivo apparent organic matter digestibility for Caphorn and Isengrain

The organic matter digestibility of both wheat cultivars did not differ between the caecectomised cockerels and the TIM-1 model: $72 \cdot 0$ (SD 2.6) \% in vivo $v .70 \cdot 6$ (SD 0.6) \% in TIM-1 for Caphorn $(P=0.580)$ and $73.0(\mathrm{SD} 2.3) \%$ in vivo v. 71.1 (SD 1.9) $\%$ in TIM-1 for Isengrain $(P=0 \cdot 252)$. Thus, TIM-1 is able to predict the digestibility of organic matter in poultry, and significant time may consequently be saved.

\section{Caphorn and Isengrain digestion in the TNO gastrointestinal model-1 compartments}

Digestibility markers (organic matter, reducing ends and end products) measured in the TIM-1 compartments after the $6 \mathrm{~h}$ digestion trial are shown in Table 2. These digestibility markers account for the transit of whole organic solids, the hydrolysis of osidic linkages and the released products, especially monomers and dimers. This allows an overview on the digestion of carbohydrates to be obtained. Overall, these markers were distributed as follows: $41.4-58.9 \%$ in
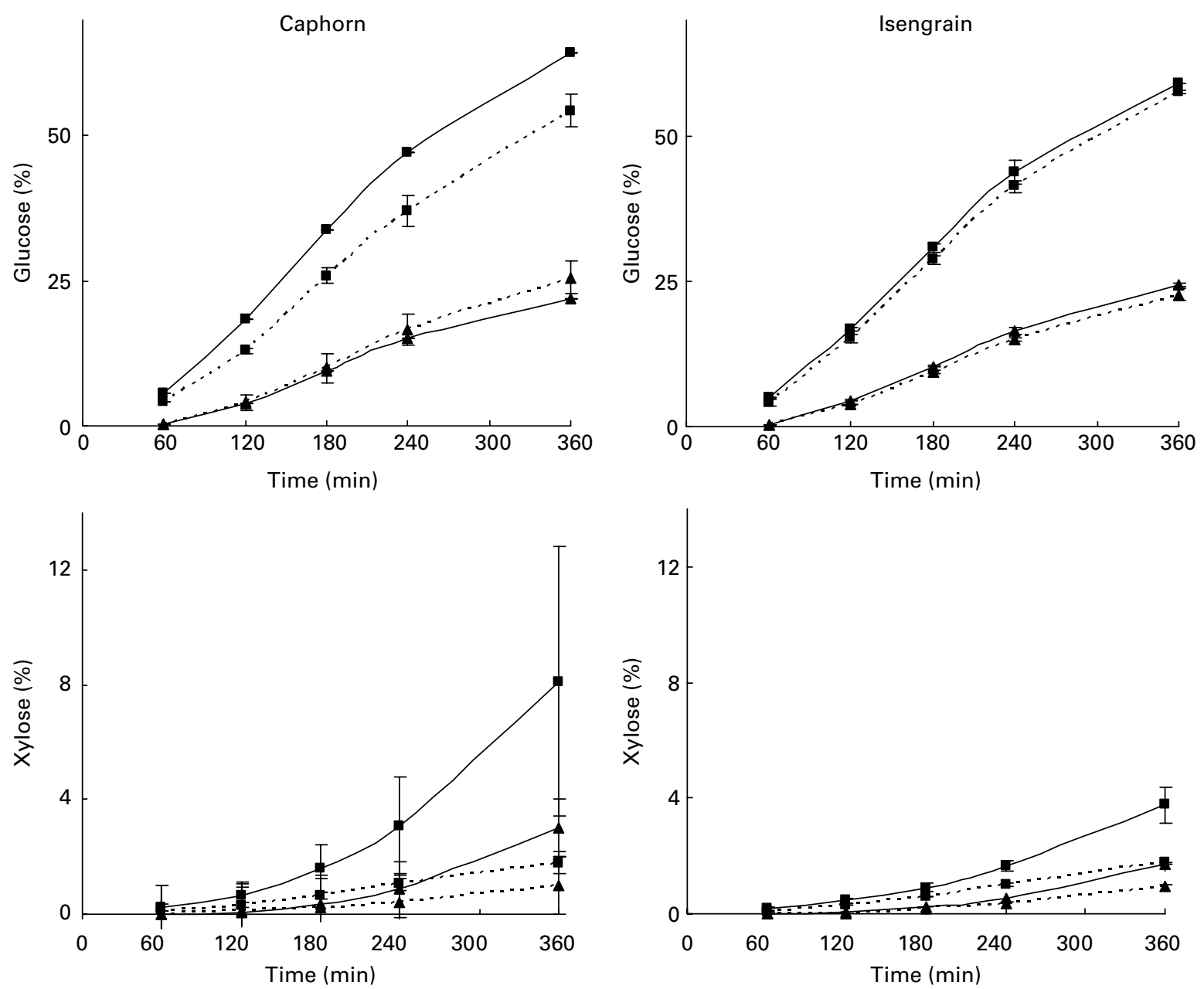

Fig. 4. Time-course appearance of glucose- (up) and xylose-containing carbohydrates (down) from Caphorn (left) and Isengrain (right) in the presence ( - ) or absence (--) of Rovabio ${ }^{\mathrm{TM}}$ in the jejunal $(\boldsymbol{\square})$ and ileal $(\boldsymbol{\Lambda})$ dialysates. The contents of glucose and xylose, among other monosaccharides, in the dialysed samples were determined using GC and are expressed as the percentage of total glucose and total xylose, respectively. Each determination was performed in triplicate. 
the jejunal dialysate; $18 \cdot 3-27 \cdot 1 \%$ in the ileal dialysate; $8 \cdot 7-$ $21 \cdot 1 \%$ in the ileal delivery; $3 \cdot 3-14.6 \%$ in the digestive residues. In the digestible fraction (jejunal + ileal dialysates) for both Caphorn and Isengrain, the value of the reducing ends is higher than that of the organic matter $(P=0.032)$, while the opposite is observed for the ileal delivery $(P=0.004)$ and residues $(P=0.026)$. This means that the organic matter of the ileal delivery and that of the residues were depleted in reducing end-containing carbohydrates, due to the hydrolysis performed by $\alpha$-amylase and other glycosidases in the proximal parts of TIM-1. The liberated mono-, di- and oligomers were able to cross the TIM- 1 membranes $(<10 \mathrm{kDa})$. In addition, in the jejunal dialysate, whatever the wheat cultivar, the value of the end products was lower than that of the organic matter and reducing ends. The ratios of the end-product value over that of the organic matter or that of the reducing ends should be indicative of the stage of the digestion of wheat carbohydrates throughout TIM-1. Finally, in the jejunal dialysates, a tendency of a higher amount of the end products liberated from Caphorn than from Isengrain was observed. This may be linked to the higher soluble carbohydrate fraction in Caphorn compared with Isengrain (Table 1), allowing more rapid digestion of Caphorn compared with Isengrain.

\section{Kinetic effects of an enzyme supplement on Caphorn and Isengrain digestibilities in TNO-gastrointestinal model-1}

Organic matter. The time courses of AOMd in TIM-1 for Caphorn and Isengrain in the presence or absence of the enzyme supplement are shown in Fig. 2. In the absence of the enzyme, the AOMd for Isengrain was found to be higher than that for Caphorn, both in the jejunal dialysate (3.3-3.9\%) at all the time intervals $(P=0.0075$ at $180 \mathrm{~min}, P=0.0014$ at $240 \mathrm{~min}$ and $P=0.0203$ at $360 \mathrm{~min})$ and in the ileal dialysate $3.4 \%(P=0.0125)$ at $180 \mathrm{~min}$ and $3.4 \%(P=0.0058)$ at $240 \mathrm{~min})$. For both cultivars, the dialysis of organic matter took place mainly in the jejunal compartment. The enzyme supplement was found to have a positive effect on the jejunal AOMd, especially at $360 \mathrm{~min}$ of digestion $(6.9 \%, P<0.0001)$, but no marked effect was observed on the ileal AOMd (no significant variation, except at $360 \mathrm{~min}(-2 \cdot 7 \%, P=0 \cdot 003))$. The effect of the enzyme supplement on the global apparent digestibility (jejunal + ileal TIM-1 compartments) was $5 \cdot 2 \%$ at $180 \mathrm{~min}(P<0.0001), 6.9 \%$ at $240 \mathrm{~min}(P<0.0001)$ and $4.2 \%$ at $360 \mathrm{~min}(P=0.003$; data not shown $)$. For Isengrain, the two curves with or without the enzyme supplement are not clearly distinct from each other, both for the jejunal and ileal dialysates, although the global effect at $360 \mathrm{~min}$ was positive $(2.9 \%, P=0.027)$. It therefore seems that the supplemented glycosidases have more rapid access to their substrates in Caphorn than in Isengrain, in line with the content of the soluble carbohydrate fraction and the degree of AX ramification.

Overall, the net cumulative effect of the enzyme supplement at $360 \mathrm{~min}$ on AOMd reached $4 \%$ for Caphorn and $3 \%$ for Isengrain. This is consistent with previous studies, which have shown a 3-5\% digestibility improvement in metabolisable energy with the same enzyme supplement in growing chickens ${ }^{(14)}$, which notably highlights the usefulness of the in vitro model as a predictor of carbohydrate digestion in poultry.

Reducing ends. The cumulative appearance of the reducing ends from supplemented and unsupplemented wheat in TIM-1 is shown in Fig. 3. A clear positive cumulative effect of the enzyme supplement on the liberated reducing ends was observed for Caphorn in the jejunal compartment (70.6\% at $360 \mathrm{~min}, P<0.0001)$ but not in the ileal one, although there was a tendency for a positive effect at $180 \mathrm{~min}$ (28.7\%, $P=0.079)$. Conversely, for Isengrain, the enzyme supplement significantly improved the liberation of the reducing ends in the ileal compartment but not in the jejunal one: $30.3 \%(P<0.0001)$ and $7.8 \%(P=0.089)$, respectively, at the end of the digestion. The cumulative effect of the enzyme supplement on the liberation of the reducing ends
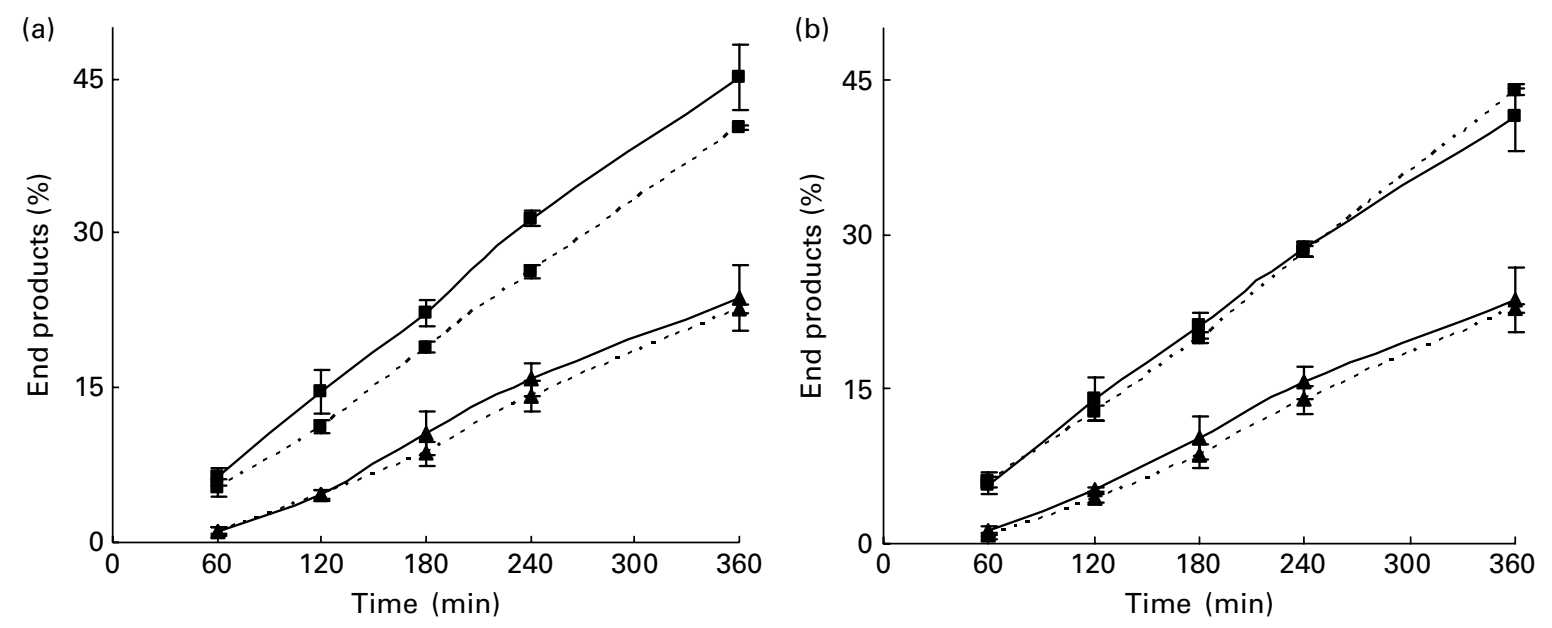

Fig. 5. Time course of the cumulative appearance of end products from (a) Caphorn and (b) Isengrain in the presence (-) or absence (---) of Rovabio ${ }^{\mathrm{TM}}$ in the jejunal $(\boldsymbol{\square})$ and ileal $(\boldsymbol{\Delta})$ dialysates. The end products glucose, maltose, maltotriose and xylobiose were identified in the high-performance anion exchange chromatography coupled with a pulsed amperometric detection chromatograms (see text for details), and their peak areas, along with the areas of minor non-identified peaks, were cumulated over the $6 \mathrm{~h}$ digestion trial in all the fractions (jejunal and ileal dialysates, ileal delivery and residues). The percentage values are relative to the total peak area. Each determination was performed in triplicate. 
in TIM-1 was $47 \cdot 2 \%(P<0 \cdot 0001)$ for Caphorn and $14 \cdot 2 \%$ for Isengrain ( $P=0.0004$; data not shown). These positive effects were essentially localised in the jejunal compartment for Caphorn and in the ileal one for Isengrain. The effect of the enzyme supplement on the liberation of the reducing ends is more pronounced than that on organic matter digestibility (Fig. 2). This suggests that large parts of the broken osidic bonds did not lead to reducing end-containing products that would cross the TIM-1 dialysis membranes.

Total monosaccharides. The time courses of glucose- and xylose-containing carbohydrate liberation in TIM-1 digestible fractions from Caphorn and Isengrain, with and without the enzyme supplement, are shown in Fig. 4. The graphs for glucose were similar to those for organic matter (Fig. 2), i.e. (1) a clear positive effect of the enzyme supplement on
Caphorn digestibility in the jejunal compartment varying from $3.6 \%(P=0.009)$ at $120 \mathrm{~min}$ up to $9.7 \%(P<0.0001)$ at $360 \mathrm{~min}$, (2) no clear effect on Caphorn digestibility in the ileal compartment and (3) less pronounced effects of the enzyme supplement on Isengrain digestibility - global effect (jejunal + ileal compartments) of $3 \cdot 1 \%(P=0.003)$ at $180 \mathrm{~min}$, $3.8 \%(P=0.009)$ at $240 \mathrm{~min}$ and $3.1 \%(P=0.031)$ at $360 \mathrm{~min}$. The similarity between the plots for organic matter and those for total glucose was well expected, since glucose largely accounts for the organic matter in mass. As regarding total xylose, the positive effect of the enzyme supplement was significant for Caphorn (an increase from $2 \cdot 8$ up to $11 \cdot 1 \%, P=0 \cdot 0003$ ) but not for Isengrain (an increase from 2.7 up to $5.5 \%, P=0.165)$. The dramatic increase in xylose liberation from Caphorn is the result of the hydrolytic activity

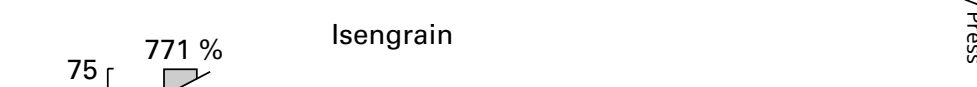

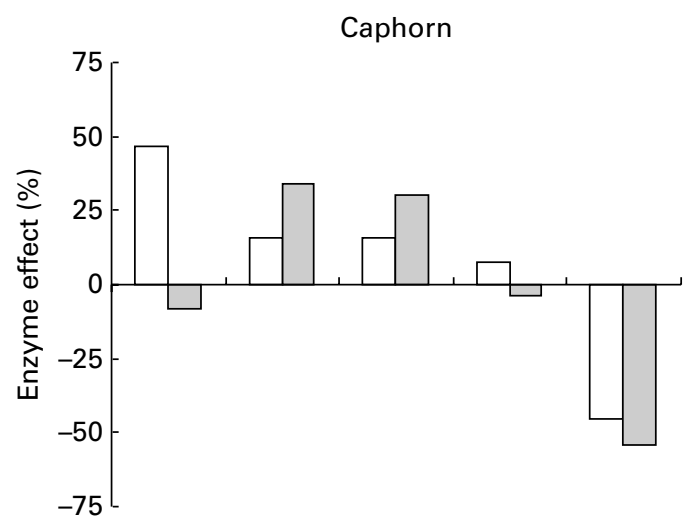
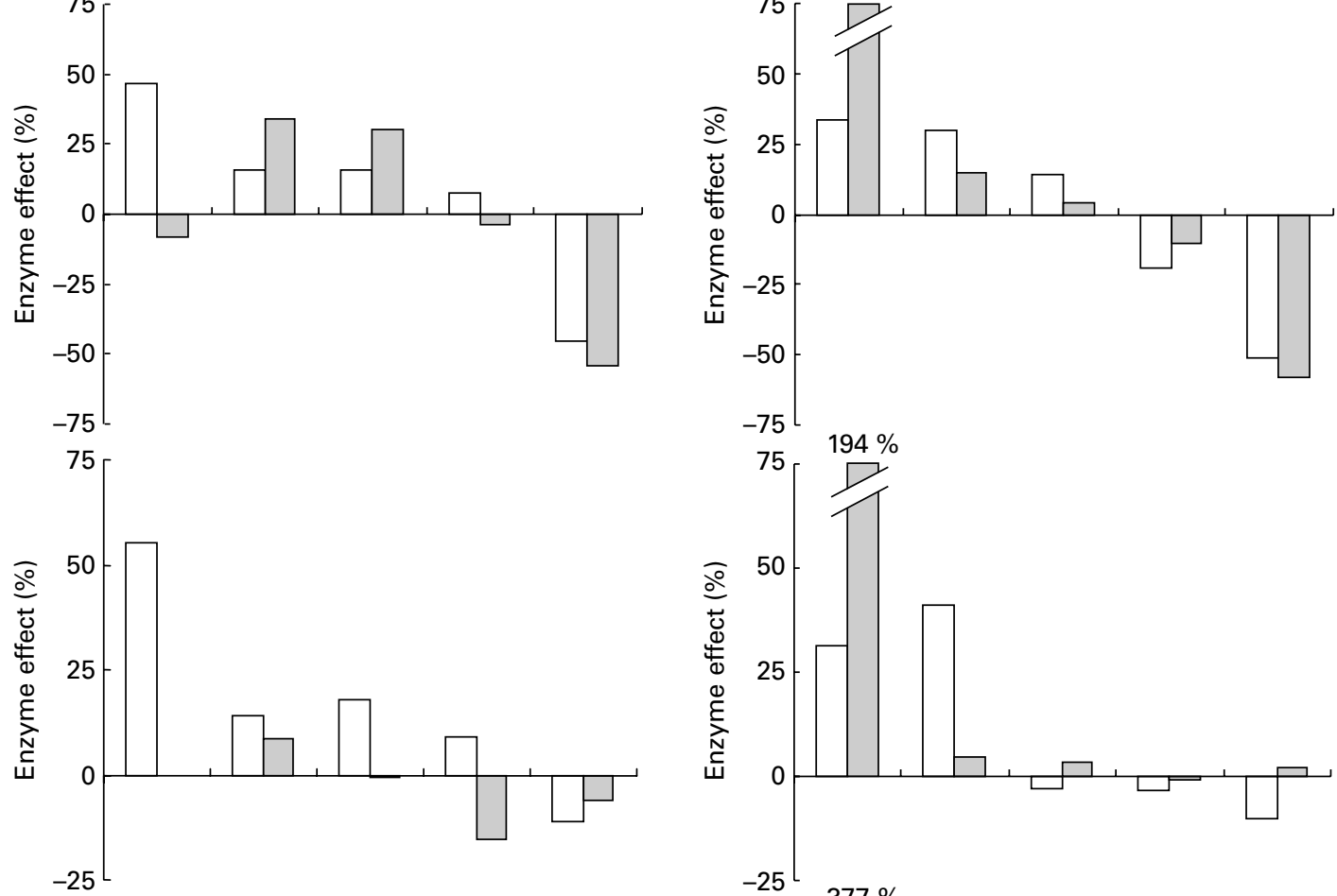

Caphorn

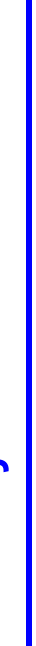
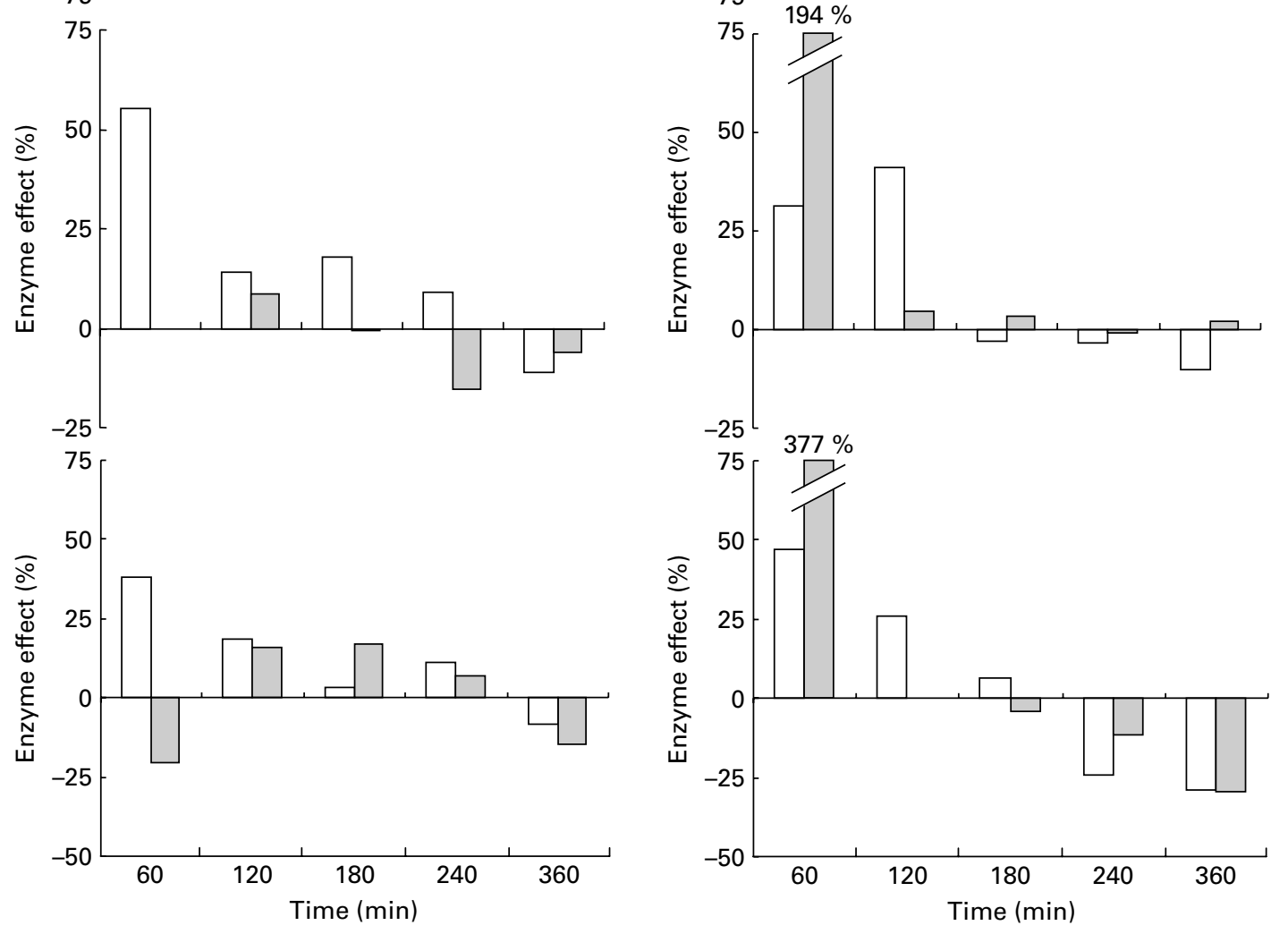

Fig. 6. Time-course effect ((peak area with the enzyme supplement/peak area without the enzyme supplement) $\times 100)$ of the enzyme supplement on the liberation of glucose (upper), maltose (medium) and xylobiose (lower) from Caphorn (left) and Isengrain (right) in the TNO gastrointestinal model-1 jejunal ( $\square$ ) and ileal $(\square)$ dialysates. The experimental deviations are not shown for clarity purposes. 
displayed by the glycosidases of the enzyme supplement, which are mainly of the xylanolytic type ${ }^{(15-17)}$. These glycosidases seem to have more difficult access to NSP in Isengrain than in Caphorn, which may be again linked to the soluble carbohydrate content and the AX ramification. It is also possible that Isengrain contains more xylanase inhibitors than Caphorn ${ }^{(23)}$.

End products. Fig. 5 shows the time courses for endproduct appearance in the jejunal and ileal dialysates from supplemented or not supplemented Caphorn and Isengrain wheat cultivars. The effect of the enzyme supplement on the digestibility of the two wheat cultivars is similar to that observed using organic matter (Fig. 2) or total glucose (Fig. 4) as digestibility markers. For both Caphorn and Isengrain, the effect on the global digestibility (jejunal + ileal dialysates) increased during digestion, culminating at $240 \mathrm{~min}: 3.0 \%(P=0.033)$ at $120 \mathrm{~min}, 7.2 \%(P<0.0001)$ at $240 \mathrm{~min}$ and $3.8 \%(P=0.008)$ at $360 \mathrm{~min}$ for Caphorn, and $3.9 \%(P=0.007)$ at $120 \mathrm{~min}, 4.5 \%(P=0.002)$ at $240 \mathrm{~min}$ and $-0.8 \%(P=0.561)$ at $360 \mathrm{~min}$ for Isengrain. The mitigation effect of the enzyme supplement at the end of the run was probably due to the depletion of the NSP enzyme amount and/or to the decrease in the amount of the substrate potentially hydrolysed.

The chronological effect of the enzyme supplement on the appearance of glucose, maltose and xylobiose is shown in Fig. 6. The enzyme preparation improved the digestion of Caphorn especially in the first fractions of the jejunal and ileal dialysates and improved that of Isengrain especially in the first fractions of the ileal dialysates. The positive effect of the enzyme supplement on the release of maltose results from better $\alpha$-amylase access to starch, as maltose is the main product of starch hydrolysis by $\alpha$-amylase ${ }^{(24)}$. Its positive effect on glucose liberation accounts for the more efficient hydrolysis of both starch and NSP, while that on xylobiose liberation is representative of only AX hydrolysis. The magnitude of the improvement of Caphorn and Isengrain digestibilities by the enzyme supplement decreased with time, which means that supplemented glycosidases, while they specifically degraded Caphorn and Isengrain NSP, were less and less active as digestion progressed. This reduction in activity may be due either to their degradation by the proteases available in TIM-1 or to a limitation in substrates.

\section{Conclusion}

In the present study, we used an integrative approach based on several digestibility markers - organic matter, reducing ends and end products - of wheat carbohydrates using TIM-1. The in vitro digestion model was found to be able to predict the digestibility of wheat organic matter in caecectomised cockerels, supporting it as a valuable prediction tool for the gastrointestinal digestion of food and feed. The integrative approach allowed an overview covering the global transit of organic matter, the degree of rupture of osidic links along with the released end products. The total monosaccharides, as determined in all TIM-1 compartments, are complementary to the three other chronological digestibility markers.

\section{Acknowledgements}

The present study was supported by Adisseo SAS Antony. The authors are very grateful to Estelle Devillard for helpful discussions and to Friedrich Rouffineau for assistance in statistical treatments. The authors' contributions were as follows: M. L. was involved in the study design and data interpretation, and wrote the manuscript; B. B. was involved in the study design and statistical analysis, and wrote the manuscript; S. E. performed the GC measurements; E. B. was responsible for the GC measurements and was involved in the data interpretation; E. H. C. was involved in the data interpretation and wrote the manuscript; P.-A. G. was the local coordinator of the TIM-1 studies; T. G. was involved in the study design and data interpretation, and edited the manuscript; E. H. A. was the coordinator of the study design and was involved in the data interpretation and in writing and editing the manuscript. The authors declare no conflict of interest.

\section{References}

1. Carre B, Idi A, Maisonnier S, et al. (2002) Relationships between digestibilities of food components and characteristics of wheats (Triticum aestivum) introduced as the only cereal source in a broiler chicken diet. Br Poult Sci $\mathbf{4 3}$, 404-415.

2. Austin SC, Wiseman J \& Chesson A (1999) Influence of nonstarch polysaccharides structure on the metabolisable energy of U.K. wheat fed to poultry. J Cereal Sci 29, 77-88.

3. Saulnier L, Sado P-E, Branlard G, et al. (2007) Wheat arabinoxylans: exploiting variation in amount and composition to develop enhanced varieties. J Cereal Sci 46, 261-281.

4. Jamroz D, Jakobsen K, Bach Knudsen KE, et al. (2002) Digestibility and energy value of non-starch polysaccharides in young chickens, ducks and geese, fed diets containing high amounts of barley. Comp Biochem Physiol A Mol Integr Physiol 131, 657-668.

5. Knudsen KEB (1997) Carbohydrate and lignin contents of plant materials used in animal feeding. Anim Feed Sci Technol 67, 319-338.

6. Fincher GB \& Stone BA (1986) Cell walls and their components in cereal grain technology. Adv Cereal Sci Technol 8, 207-295.

7. Izydorczyk MS \& Biliaderis CG (1995) Cereal arabinoxylans: advances in structure and physicochemical properties. Carbohydr Polym 28, 33-48.

8. McCracken KJ \& Quintin G (2000) Metabolisable energy content of diets and broiler performance as affected by wheat specific weight and enzyme supplementation. $\mathrm{Br}$ Poult Sci 41, 332-342.

9. Wu YB, Ravindran V, Thomas DG, et al. (2004) Influence of phytase and xylanase, individually or in combination, on performance, apparent metabolisable energy, digestive tract measurements and gut morphology in broilers fed wheat-based diets containing adequate level of phosphorus. Br Poult Sci 45, 76-84.

10. Choct M, Kocher A, Waters DLE, et al. (2004) A comparison of three xylanases on the nutritive value of two wheats for broiler chickens. Br J Nutr 92, 53-61.

11. Minekus M, Marteau P, Havenaar R, et al. (1995) A multicompartmental dynamic computer-controlled model simulating the stomach and small-intestine. ATLA 23, 197-209.

12. Haraldsson AK, Rimsten L, Alminger M, et al. (2005) Digestion of barley malt porridges in a gastrointestinal model: 
iron dialysability, iron uptake by Caco- 2 cells and degradation of [beta]-glucan. J Cereal Sci 42, 243-254.

13. Fassler C, Arrigoni E, Venema K, et al. (2006) Digestibility of resistant starch containing preparations using two in vitro models. Eur J Nutr 45, 445-453.

14. Maisonnier-Grenier S, Clavurier K, Saulnier L, et al. (2006) Biochemical characteristics of wheat and their relation with apparent metabolisable energy value in broilers with or without non-starch polysaccharide enzyme. I Sci Food Agric 86, 1714-1721.

15. Karboune S, Geraert PA \& Kermasha S (2008) Characterization of selected cellulolytic activities of multi-enzymatic complex system from Penicillium funiculosum. J Agric Food Chem 56, 903-909.

16. Karboune S, L'Hocine L, Anthoni J, et al. (2009) Properties of selected hemicellulases of a multi-enzymatic system from Penicillium funiculosum. Biosci Biotechnol Biochem 73, $1286-1292$.

17. Guais O, Borderies G, Pichereaux C, et al. (2008) Proteomics analysis of 'Rovabio Excel', a secreted protein cocktail from the filamentous fungus Penicillium funiculosum grown under industrial process fermentation. I Ind Microbiol Biotechnol 35, 1659-1668.
18. Lessire M (1990) Effect of feeding technique, ad libitum, dry or wet force feeding, on the metabolisable energy values of raw materials for poultry. Br Poult Sci 31, 785-793.

19. Andrews WH (1996) AOAC INTERNATIONAL's three validation programs for methods used in the microbiological analysis of foods. Trends Food Sci Technol 7, 147-151.

20. Dervilly G, Saulnier L, Roger P, et al. (2000) Isolation of homogeneous fractions from wheat water-soluble arabinoxylans. Influence of the structure on their macromolecular characteristics. J Agric Food Chem 48, 270-278.

21. Bailey MJ, Biely P \& Poutanen K (1992) Interlaboratory testing of methods for assay of xylanase activity. J Biotechnol 23, 257-270.

22. Bonnin E, Daviet S, Sorensen JF, et al. (2006) Behaviour of family 10 and 11 xylanases towards arabinoxylans with varying structure. J Sci Food Agric 86, 1618-1622.

23. Bonnin E, Daviet S, Gebruers K, et al. (2005) Variation in the levels of the different xylanase inhibitors in grain and flour of 20 French wheat cultivars. J Cereal Sci 41, 375-379.

24. Robyt JF \& French D (1970) The action pattern of porcine pancreatic alpha-amylase in relationship to the substrate binding site of the enzyme. J Biol Chem 245, 3917-3927. 